\title{
Seroepidemiology of Hepatitis C Among Drug Users at a Detoxification Center in Southeast China
}

\author{
Dangui Zhang ${ }^{\# 1}$, Xubin Zhang ${ }^{\# 2}$, Lu Xu ${ }^{2}$, D. Lorne Tyrrell ${ }^{3}$, Michael Houghton ${ }^{3}$ and William \\ Ba-Thein ${ }^{4,5,{ }^{*}}$ \\ ${ }^{1}$ Research Center of Translational Medicine, The Second Affiliated Hospital of Shantou University Medical College, Shantou, China \\ ${ }^{2}$ Department of Disease Control, Shantou Center for Disease Control and Prevention, Shantou, China \\ ${ }^{3}$ Department of Medical Microbiology and Immunology and Li Ka Shing Institute of Virology, University of Alberta, Edmonton, Canada \\ ${ }^{4}$ Department of Microbiology and Immunology, Shantou University Medical College, Shantou, China \\ ${ }^{5}$ Clinical Research Unit, Shantou University Medical College, Shantou, China \\ "Corresponding author: Clinical Research Unit, Shantou University Medical College, Science and Technology Building, 22 Xinling Road, Shantou, China. Tel: +86-075488900419, \\ Email: wbathein@stu.edu.cn \\ \# These authors are contributed equally as the first author.
}

Received 2019 October 30; Revised 2020 February 11; Accepted 2020 March 15

\begin{abstract}
Background: Hepatitis C virus (HCV) infection is prevalent worldwide, especially among drug users. The epidemiology of HCV is rarely reported among drug users in developing countries, including China.

Objectives: We aimed to describe the seroepidemiology of HCV infection in drug users at a Detoxification Center in Southeast China. Methods: With approval from the Shantou Center for Disease Control, the archived data of drug users $(n=5,228)$ at the largest monitored-detoxification center in Shantou during 2011 - 2017 were analyzed for demographics, risk behaviors, and HCV serology. Results: Among HCV-tested drug users, 36.9\% (1930/5228) were people who inject drugs (PWID). The mean annual HCV seroprevalence rate over the seven-year study period was $36.3 \%$ for all drug users, including $67.3 \%$ and $16.6 \%$ for PWID and non-PWID, respectively, with the highest prevalence (78.1\%) in 2017 and the lowest prevalence (58.6\%) in 2015 for PWID. Independent risk factors of HCV infection identified by multiple logistic regression analysis were engaging in unprotected $\operatorname{sex}(\mathrm{OR}=1.553,95 \% \mathrm{CI}=1.078-2.236)$, injecting drugs (10.28, 8.98 - 11.763), and sharing needles/syringes $(2.24,1.129-4.445)$ for all drug users and sharing needles/syringes $(2.062,1.438$ - 2.957) for PWID.

Conclusions: This study reports the seroepidemiology of drug users in the monitored Detoxification Center in Southeast China. A relatively high HCV positivity rate, especially among PWID, their high-risk behaviors and low education, and lack of institutional interventions of HCV monitoring and transmission call for government-sponsored educational programs to raise drug users' awareness of the risk of HCV infection and other co-infections and monitoring of the infectious status and treatment of HCV-infected drug users.
\end{abstract}

Keywords: Hepatitis C, Epidemiology, Health Risk Behaviors, Risk Factors, Drug Users

\section{Background}

Hepatitis C, a blood-borne infection caused by the hepatitis $\mathrm{C}$ virus (HCV), poses a global healthcare burden, especially due to its consequences such as cirrhosis, hepatocellular carcinoma, liver failure, and death (1). People who inject drugs (PWID) are the main population with high HCV incidence and prevalence in most of the reporting countries (2-4). The regional prevalence of HCV infection in PWID varies widely, including 64.7\% in Eastern Europe, 61.9\% in Latin America, 57.1\% in Australia, 55.2\% in North America, 53.2\% in Western Europe, and 38.6\% in South Asia $(3,5)$.

Sharing needles/syringes or drug preparation and in- jection materials (such as cookers, cotton, water, ties, or alcohol swabs), duration of drug injection, using and injecting multiple types of drugs, unprotected sex, and male homosexual activity are considered the risk behaviors for HCV infection in PWID (6-9). Although these risk factors are variable depending on reporting countries, drug-injecting practices and sexual contact remain strongly associated with HCV infection (10).

Globally, there are around 13 million PWID, of which $67 \%$ have hepatitis C. Also, PWID account for more than half of the 2.2 million HCV/HIV (human immunodeficiency virus) co-infections worldwide (11). In China, there were about 2.4 million known drug users in 2018, with most of 
them residing in Guangdong Province in the southeast of China (12). Guangdong was reportedly one of the Chinese provinces with the highest HCV infection rate among PWID in 2008 (10) and drug users in 2011 - 2013 (13). The current status of HCV prevalence in Guangdong PWID is, however, unknown.

\section{Objectives}

This study aimed to describe the serological prevalence of HCV among drug users during 2011 - 2017 in a Detoxification Center in Shantou City, Guangdong Province.

\section{Methods}

\subsection{Ethics Statement}

This study was approved by the Ethics Committees of Shantou University Medical College and the Shantou Center for Disease Control and Prevention (CDC).

\subsection{Study Population/Site}

The study population was the drug users in the largest monitored-Detoxification Center in Shantou City, one of the 87 national HCV monitoring sentinels with mandatory screening for HCV by serology in focus groups including PWID. Shantou is the prefectural city of Guangdong Province with a population of 5.6 million as of 2017 (14).

\subsection{HCV Screening}

The HCV screening was done as an annual routine by the Shantou CDC. Two third-generation enzyme immunoassay (EIA) kits were used to test anti-HCV antibodies, one for screening (Kehua Biotech Co. Ltd, Shanghai, China) and the other for confirmation (Abbott HCV EIA 2.0 Abbott Laboratories, North Chicago, Illinois, USA). The samples positive in both tests were merely considered HCVpositive.

\subsection{Data Collection and Analysis}

Self-reported data including demographics, drug usage and practices, and sexual practices were collected from all the participants by the Shantou CDC.

The data were analyzed by SPSS version 13 (SPSS, Chicago, IL). Categorical variables, such as gender, education, origin of residence, marital status, and HCV test results, were analyzed by the chi-square test. Continuous variables, such as age, were analyzed by the $t$-test (for normally distributed data) or Mann-Whitney U test (for non-normally distributed data). The normality of continuous variables was tested by the Kolmogorov-Smirnov test. A multiple logistic regression model (Enter method) was used to assess the effect of different variables on HCV positivity. All statistical tests were two-tailed and P value $<0.05$ was considered statistically significant.

\section{Results}

4.1. Sociodemographic Characteristics of Drug Users and HCV Positivity

As represented in Table 1, the demographic variables in all drug users and HCV-positive drug users, respectively, were as follows: males (92.5\%, 4,837/5,228 and 93.5\%, 1,746/1,868), non-local residents (13.1\%, 685/5,228 and $12.7 \%, 237 / 1,868)$, low education, i.e., below high-school education, (89.7\%, 4,688/5,228 and 89.5\%, 1,672/1,868), and married/living together (57.5\%, 3,008/5,228 and $58.0 \%, 1,084 / 1,868)$. Moreover, PWID accounted for $36.9 \%$ $(1,930 / 5,228)$ of all drug users.

\subsection{HCV Seroprevalence in Drug Users}

As represented in Figure 1, overall, HCV Ab was positive in $35.7 \%(1,868 / 5,228)$ of all the drug users, including 67.2\% (1,296/1,930) of PWID and 17.3\% (572/3,298) of nonPWID. The HCV positivity was significantly associated with older age $(\mathrm{P}=0.019)$ and low education $(\mathrm{P}<0.001)$, but not with gender, the origin of residence, or marital status. The mean annual HCV seroprevalence rate over the sevenyear study period was $36.3 \%$ for all drug users, including $67.3 \%$ and $16.6 \%$ for PWID and non-PWID, respectively, with the highest prevalence (78.1\%) in 2017 and the lowest prevalence (58.6\%) in 2015 for PWID. Significant differences were found in HCV positivity between different years for all drug users and PWID $(\mathrm{P}<0.001)$.

\subsection{High-risk Behaviors of Drug Users}

As represented in Figure 2, nearly 90\% of drug users $(4,752 / 5,228)$ or PWID $(1,770 / 1,930)$ did not use condoms whenever they had sex. Besides, $46.0 \%$ of drug users who were currently sexually active $(985 / 2,142)$ had sex with prostitutes during the previous month, 77.2\% (760/985) of which were without using condoms (data not shown). Engaging in unprotected sex was significantly associated with HCV infection for all drug users $(\mathrm{P}=0.002)$ or PWID ( $\mathrm{P}$ $=0.016$ ) (data not shown). Among PWID, 33.0\% (637/1930) shared needles or syringes with others every time.

\subsection{Risk Factors of HCVInfection in Drug Users}

Multiple regression analysis (Figure 3) showed that three types of behaviors, viz. engaging in unprotected sex $(\mathrm{OR}=1.553,95 \% \mathrm{CI}=1.078-2.236)$, injecting drugs (10.28, 8.98-11.763), and sharing needles/syringes (2.24,1.129 - 4.445), were independent risk factors of HCV infection 


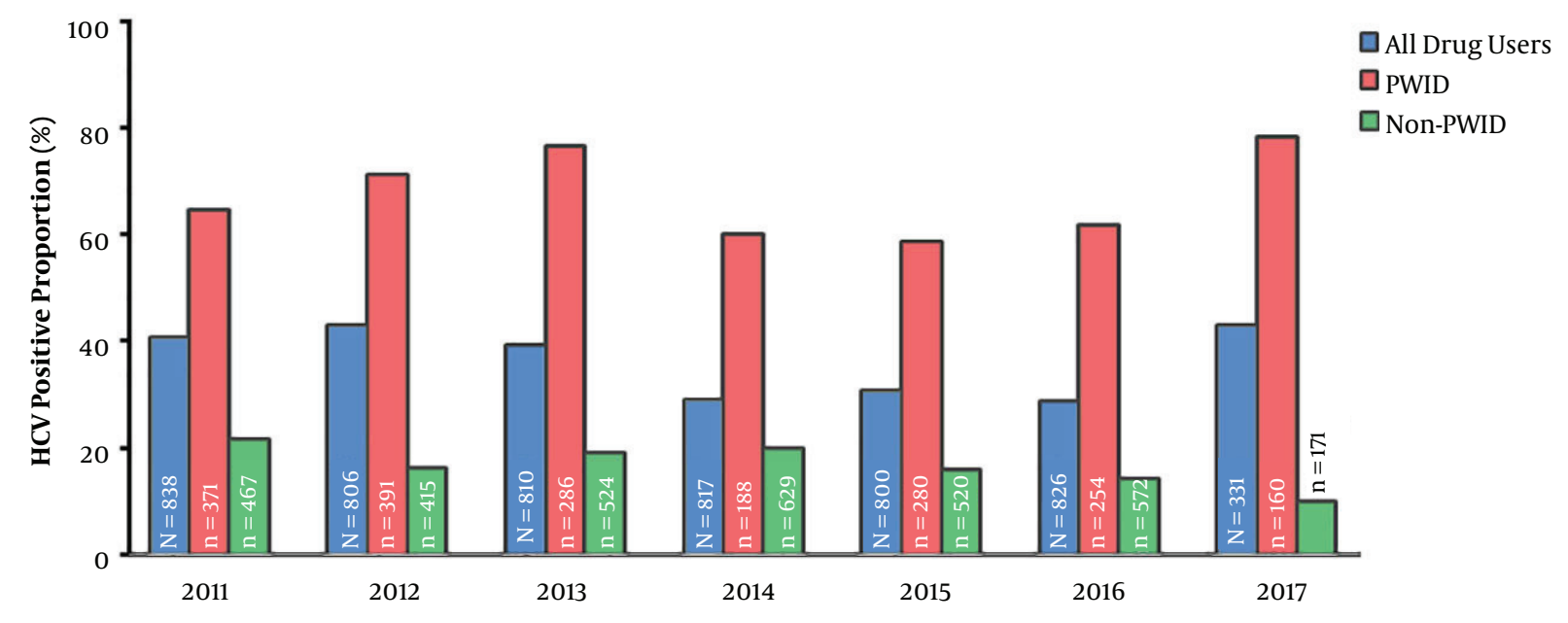

Figure 1. HCV seroprevalence proportion (\%) of drug users in the Shantou Detoxification Center (2011 - 2017). PWID, people who inject drugs.
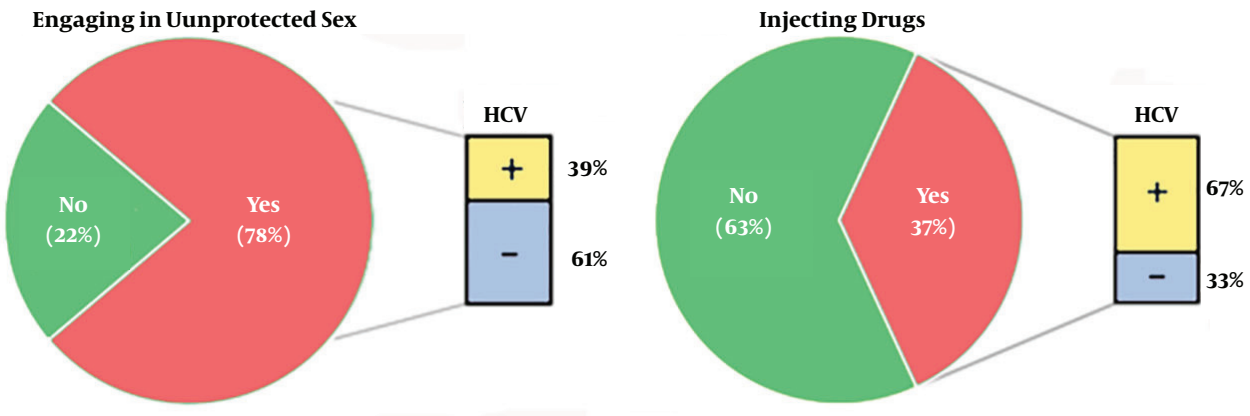

All Drug Users
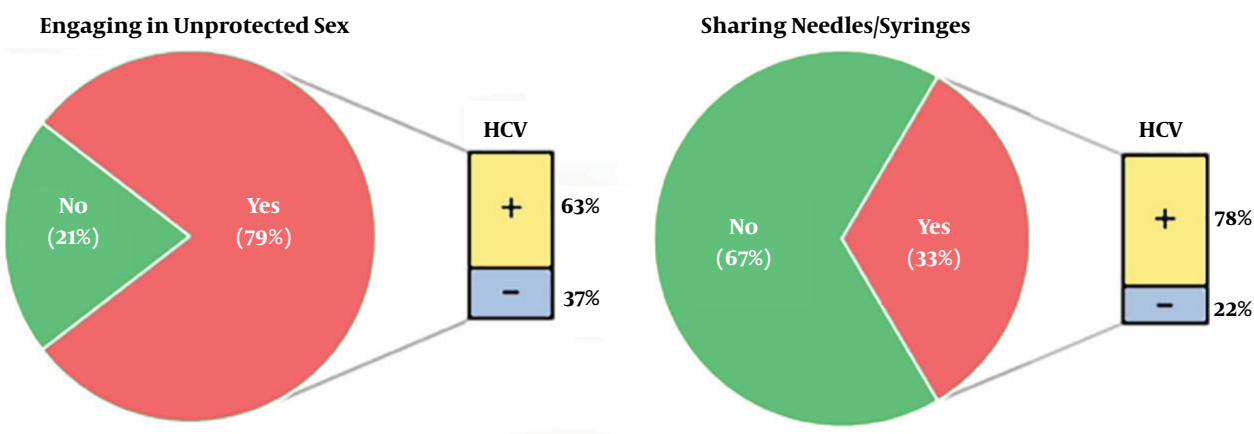

PWID

Figure 2. High-risk behaviors and HCV positivity of drug users in the Shantou Detoxification Center (2011 - 2017). PWID, people who inject drugs.

for drug users. For PWID, sharing needles/syringes (2.062, 1.438 - 2.957) was the only independent risk factor (data not shown).

\section{Discussion}

This study reports for the first time the HCV seroprevalence and high-risk behaviors of drug users in the 


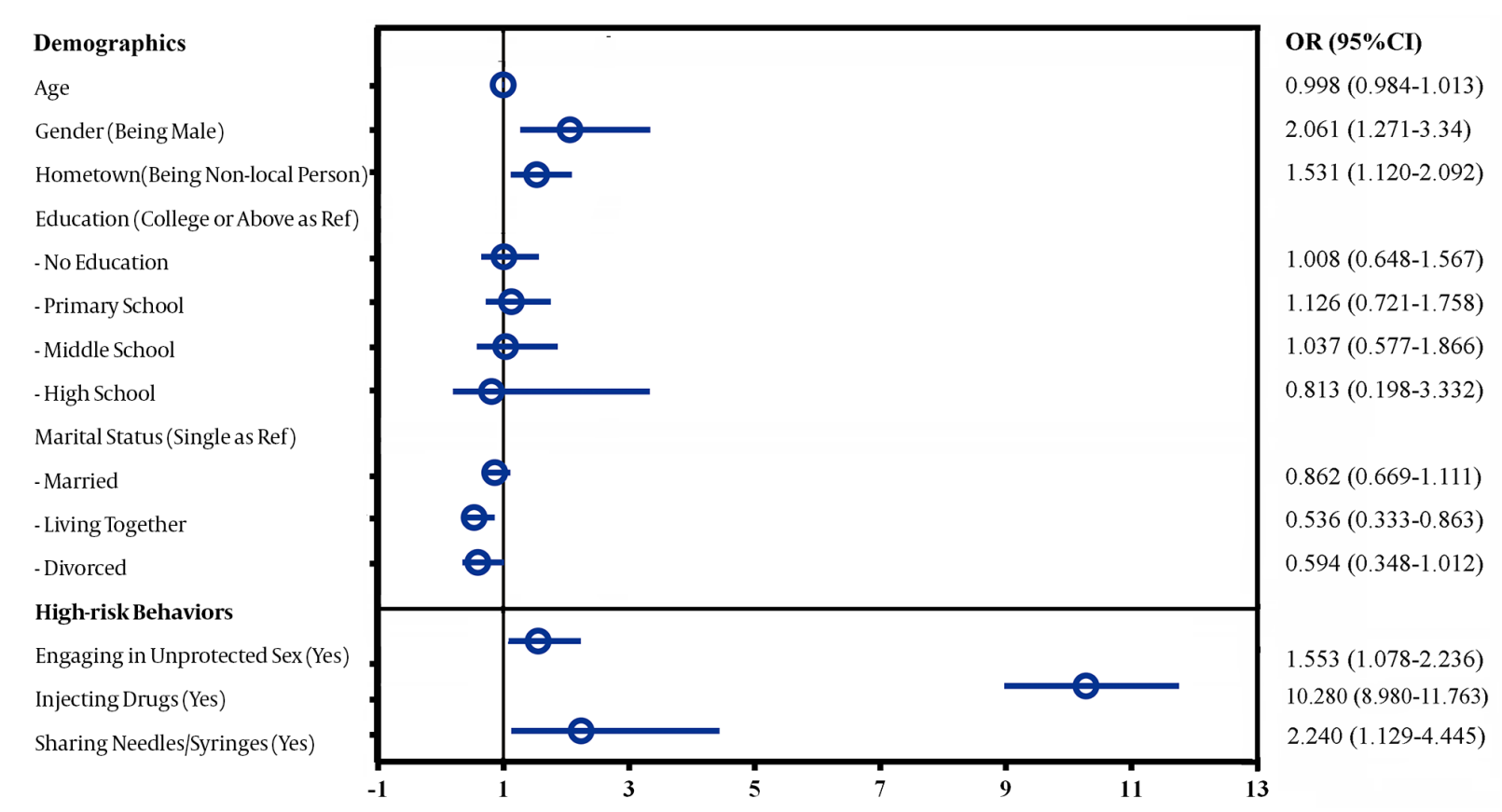

Figure 3. Multiple logistic regression analysis of HCV positivity in Shantou drug users. OR, odds ratio.

largest Detoxification Center in Shantou City, Guangdong Province, China.

\subsection{HCV Epidemiology}

Guangdong Province, which is the home of nearly 1/6 of drug users in China (11), reported an HCV positive rate of 46.5\% among its drug users during 2011 - 2013 (15). Our study setting in Shantou, a prefectural-level City of Guangdong Province, had a similarly high positive rate (40.9\%) among drug users during the same period (Figure 1).

Currently, PWID are the main target population for the prevention of HCV infection in many parts of the world. The HCV prevalence in PWID varies considerably across countries (3) or even within a country and over time. The HCV prevalence (67.2\%) in Shantou PWID is slightly lower than that of Hong Kong PWID during 2013 - 2014 (76.4\%) (16), and similar to the global prevalence (67\%) (17); however, a very high prevalence up to $81.9 \%$ was reported during 2008 - 2011 in the southwest and central parts of China (7). One likely reason could be the special geographic factor, as southwest and central China is known as "the China Channel" for opium trafficking from the production bases in "the golden triangle" to other regions in China (9).

\subsection{HCV Transmission Risk}

Some modes of HCV transmission among drug users are well recognized (18) as unsafe sex (13) and high-risk sex- ual practices such as homosexual activity (19). Sharing injecting equipment such as needles and syringes is also considered a significant risk factor for HCV infection in PWID (20). These also hold true for Shantou PWID.

Because of the shared modes of transmission, people at risk for HCV infection are also at risk for hepatitis B virus (HBV) or HIV infection. It is estimated that HCV-HBV coinfection affects an estimated 2.6 million PWID globally (17). Besides, HCV-positive PWID are at disproportionately high risk of HIV infection, as is evident from the fact that PWID account for more than half of the 2.2 million HCV/HIV co-infections worldwide $(17,21)$ and yet, $40 \%$ to $85 \%$ of persons infected with HCV are reportedly not aware of their HCV infection status (22). In China, 15\% of PWID in Yunnan Province were co-infected with HCV/HIV during 2009 - 2011 (23). Therefore, the risk of HCV/HIV co-infection in Shantou PWID cannot be ignored and screening should be done.

Further, PWID not only are ignorant of their risk of HCV infection or necessity for testing (20) but also have no understanding of HCV test results and health implications (24). The high-risk behaviors of PWID in this study were most likely due to their low health literacy because people with less than high school education are known to have low health literacy (25) and the majority (> 89\%) of the drug users or HCV-positive drug users in this study had low education.

As reported previously in Iran (26), there is a significant 


\begin{tabular}{|c|c|c|}
\hline & Total $(\mathrm{N}=5228)$ & HCV Positive $(\mathrm{N}=1868)$ \\
\hline \multicolumn{3}{|l|}{ Gender } \\
\hline Male & $4837(92.5)$ & $1746(93.5)$ \\
\hline Female & $391(7.5)$ & $122(6.5)$ \\
\hline Age $^{\mathrm{b}}$ & $32.91 \pm 8.8$ & $33.29 \pm 8.5$ \\
\hline \multicolumn{3}{|l|}{ Origin of residence } \\
\hline Local person & $4543(86.9)$ & $1631(87.3)$ \\
\hline Non-local person & $685(13.1)$ & $237(12.7)$ \\
\hline \multicolumn{3}{|l|}{ Education $^{c}$} \\
\hline No education & $298(5.7)$ & $133(7.1)$ \\
\hline Primary school & $2267(43.4)$ & $849(45.4)$ \\
\hline Middle school & $2123(40.6)$ & $690(36.9)$ \\
\hline High school & $318(6.1)$ & $121(6.5)$ \\
\hline College or above & $48(0.9)$ & $13(0.7)$ \\
\hline Missing data & $174(3.3)$ & $62(3.4)$ \\
\hline \multicolumn{3}{|l|}{ Marital status } \\
\hline Single & $1884(36.0)$ & $650(34.8)$ \\
\hline Married & $2614(50.0)$ & $940(50.3)$ \\
\hline Living together & $394(7.5)$ & $144(7.7)$ \\
\hline Divorced & $336(6.5)$ & $134(7.2)$ \\
\hline \multicolumn{3}{|l|}{$\begin{array}{l}\text { People who inject drugs } \\
(\text { PWID })^{c}\end{array}$} \\
\hline Yes & $1930(36.9)$ & $1296(69.4)$ \\
\hline No & $3298(63.1)$ & $572(30.6)$ \\
\hline
\end{tabular}

${ }^{\mathrm{a}}$ Values are expressed as No. (\%) or mean $\pm \mathrm{SD}$.

${ }^{\mathrm{b}} \mathrm{P}<0.05$ by $t$-test.

${ }^{\mathrm{C}} \mathrm{P}<0.01$ by chi-square test for HCV-positive vs. HCV-negative, as diagnosed by two HCV-Ab tests (see methods for detail).

risk of intrafamilial transmission because $20.7 \%$ of HCVpositive drug users in this study were either married or living together. Besides, $12.7 \%$ (237/1,868) of HCV-positive drug users were migrants, who could serve HCV carriers for cross-province transmission.

It is concerning that our study setting only did HCV screening without offering interventions, such as riskreduction education, HCV treatment, or HCV-RNA testing for monitoring the infectious period. Without intervention measures, there remain the risks of HCV infection in drug users who are still HCV-negative and HCV transmission among family members of HCV-positive drug users.

\subsection{Study Limitations}

Although there are three Detoxification centers in Shantou, our study setting is the largest and the only mon- itored center for $\mathrm{HCV}$ infection. Therefore, the results presented herein represent only reported drug users in the monitored Center in Shantou. Besides, we could not report HCV incidence because HCV antibody tests used in this study could not distinguish acute from chronic HCV infection. The HCV/HIV co-infection rate was not known as relevant data were not available. We also cannot assure the credibility of self-reported personal behaviors about drugs and sexual activities.

\subsection{Conclusions}

This study provides HCV seroepidemiology and highrisk behaviors among drug users in the monitored Detoxification Center in Shantou. The study findings should lay the groundwork for future interventions such as government-sponsored educational programs to raise drug users' awareness of HCV and other co-infections, and monitoring of the infection status and treatment of HCVinfected drug users.

\section{Footnotes}

Authors' Contribution: Dangui Zhang, Xubin Zhang, and William Ba-Thein designed the study. Xubin Zhang and $\mathrm{Lu} \mathrm{Xu}$ collected the data. Dangui Zhang analyzed the data. Dangui Zhang and William Ba-Thein interpreted the data. Dangui Zhang wrote the manuscript. Lorne Tyrrell, Michael Houghton, and William Ba-Thein edited the manuscript.

Conflict of Interests: The authors declare that they have no competing interests.

Ethical Approval: This study was approved by the Ethics Committees of Shantou University Medical College and the Shantou Center for Disease Control and Prevention (CDC).

Funding/Support: This work was supported by the Oxford Clinical Research Project (grant no. LD0701), the Li Ka Shing Foundation, and the Health, Science, and Technology Planning Project of Shantou City, China, 2017.

\section{References}

1. Messina JP, Humphreys I, Flaxman A, Brown A, Cooke GS, Pybus OG, et al. Global distribution and prevalence of hepatitis $C$ virus genotypes. Hepatology. 2015;61(1):77-87. doi: 10.1002/hep.27259. [PubMed: 25069599]. [PubMed Central: PMC4303918].

2. Zare F, Fattahi MR, Sepehrimanesh M, Safarpour AR. Economic burden of hepatitis $C$ virus infection in different stages of disease: A report from Southern Iran. Hepat Mon. 2016;16(4). e32654. doi: 10.5812/hepatmon.32654. [PubMed: 27257424]. [PubMed Central: PMC4887962].

3. Degenhardt L, Peacock A, Colledge S, Leung J, Grebely J, Vickerman P, et al. Global prevalence of injecting drug use and sociodemographic characteristics and prevalence of HIV, HBV, and HCV in people who inject drugs: A multistage systematic review. Lancet 
Glob Health. 2017;5(12):e1192-207. doi: 10.1016/S2214-109X(17)30375-3. [PubMed: 29074409]. [PubMed Central: PMC5683738].

4. Fattahi MR, Safarpour A, Sepehrimanesh M, Hosseini Asl SM, Mohamaddoust $F$. The prevalence of hepatitis $C$ virus infection and its related risk factors among the rural population of Fars Province, Southern Iran. Hepat Mon. 2015;15(2). e24734. doi: 10.5812/hepatmon.24734. [PubMed: 25788957]. [PubMed Central: PMC4350250].

5. Granados-Garcia V, Flores YN, Diaz-Trejo LI, Mendez-Sanchez L, Liu $S$, Salinas-Escudero G, et al. Estimating the prevalence of hepatitis $\mathrm{C}$ among intravenous drug users in upper middle income countries: A systematic review and meta-analysis. PLoS One. 2019;14(2). e0212558. doi: 10.1371/journal.pone.0212558. [PubMed: 30807590]. [PubMed Central: PMC6391024].

6. Cox J, Morissette C, De P, Tremblay C, Allard R, Graves L, et al. Access to sterile injecting equipment is more important than awareness of HCV status for injection risk behaviors among drug users. Subst Use Misuse. 2009;44(4):548-68. doi: 10.1080/10826080802544349. [PubMed: 19242863]. [PubMed Central: PMC2929254].

7. Hahn JA, Evans JL, Davidson PJ, Lum PJ, Page K. Hepatitis C virus risk behaviors within the partnerships of young injecting drug users. Addiction. 2010;105(7):1254-64. doi: 10.1111/j.1360-0443.2010.02949.x. [PubMed: 20491725]. [PubMed Central: PMC2907461].

8. Li L, Assanangkornchai S, Duo L, McNeil E, Li J. Risk behaviors, prevalence of HIV and hepatitis $C$ virus infection and population size of current injection drug users in a China-Myanmar border city: Results from a Respondent-Driven Sampling survey in 2012. PLoS One. 2014;9(9). e106899. doi: 10.1371/journal.pone.0106899. [PubMed: 25203256]. [PubMed Central: PMC4159231].

9. Jin F, Matthews GV, Grulich AE. Sexual transmission of hepatitis C virus among gay and bisexual men: A systematic review. Sex Health. 2017;14(1):28-41. doi: 10.1071/SH16141. [PubMed: 27712618].

10. Xia X, Luo J, Bai J, Yu R. Epidemiology of hepatitis C virus infection among injection drug users in China: Systematic review and meta-analysis. Public Health. 2008;122(10):990-1003. doi: 10.1016/j.puhe.2008.01.014. [PubMed:18486955].

11. Guangdong Provincial Narcotics Control Commission. Press conference of narcotics effectiveness in Guangdong in 2016.2016, [cited 2016 Jun 27]. Available from: http://www.gdjd626.com/\#/index.

12. National Narcotics Control Office. National Narcotics control report in 2018. 2018, [cited 2019 Jun 18]. Available from: http://www.gov.cn/ xinwen/2019-06/18/content_5401230.htm.

13. Wu J, Huang J, Xu D, Lu C, Deng X, Zhou X. Infection status and risk factors of HIV, HBV, HCV, and syphilis among drug users in Guangdong, China-a cross-sectional study. BMC Public Health. 2010;10:657. doi: 10.1186/1471-2458-10-657. [PubMed: 21040549]. [PubMed Central: PMC3091571].

14. Shantou Statistical Information Network. Statistical report of national economic and social development in Shantou in 2017. 2018, [cited 2020 Feb 4]. Available from: http://www.tjcn.org/tjgb/19gd/35444_ 5.html.
15. Huang XM, Lin P, Li Y, Fu XB. Analysis on HCV seroprevalence and related risk factors among drug users, Guangdong Province, 2011-2013. Prev Med Trib. 2016;22:88-94.

16. Chan DP, Lee KC, Lee SS, Tan TY.Community-based molecular epidemiology study of hepatitis $C$ virus infection in injection drug users. Hong Kong Med J. 2017;23 Suppl 5(4):27-30. [PubMed: 28943522].

17. World Health Organization. People who inject drugs. 2020, [cited 2020 Feb 4]. Available from: http://www.who.int/hiv/topics/idu/en.

18. Zhou B, Cai GFF, Lv HKK, Xu SFF, Wang ZTT, Jiang ZGG, et al. Factors correlating to the development of hepatitis $C$ virus infection among drug users-findings from a systematic review and meta-analysis. Int J Environ Res Public Health. 2019;16(13). doi: 10.3390/ijerph16132345. [PubMed: 31269774]. [PubMed Central: PMC6651123].

19. Turner JM, Rider AT, Imrie J, Copas AJ, Edwards SG, Dodds JP, et al. Behavioural predictors of subsequent hepatitis $C$ diagnosis in a UK clinic sample of HIV positive men who have sex with men. Sex Transm Infect. 2006;82(4):298-300. doi: 10.1136/sti.2005.018366. [PubMed: 16877578]. [PubMed Central: PMC2564713].

20. Aitken CK, Agius PA, Higgs PG, Stoove MA, Bowden DS, Dietze PM. The effects of needle-sharing and opioid substitution therapy on incidence of hepatitis $C$ virus infection and reinfection in people who inject drugs. Epidemiol Infect. 2017;145(4):796-801. doi: 10.1017/S0950268816002892. [PubMed: 27927256].

21. Zamani S, Radfar R, Nematollahi P, Fadaie R, Meshkati M, Mortazavi $S$, et al. Prevalence of $\mathrm{HIV} / \mathrm{HCV} / \mathrm{HBV}$ infections and drugrelated risk behaviours amongst IDUs recruited through peerdriven sampling in Iran. Int J Drug Policy. 2010;21(6):493-500. doi: 10.1016/j.drugpo.2010.04.006. [PubMed: 20483578].

22. Spach DH. HCV epidemiology in the United States. 2016, [cited 2020 Feb 4]. Available from: http://www.hepatitisc.uw.edu/go/screeningdiagnosis/epidemiology-us/core-concept/all.

23. Zhou YH, Yao ZH, Liu FL, Li H, Jiang L, Zhu JW, et al. High prevalence of HIV, HCV, HBV and co-infection and associated risk factors among injecting drug users in Yunnan Province, China. PLoS One. 2012;7(8). e42937. doi: 10.1371/journal.pone.0042937. [PubMed: 22916185]. [PubMed Central: PMC3420897].

24. Jordan AE, Masson CL, Mateu-Gelabert P, McKnight C, Pepper N, Bouche $\mathrm{K}$, et al. Perceptions of drug users regarding hepatitis $\mathrm{C}$ screening and care: A qualitative study. Harm Reduct J. 2013;10:10. doi: 10.1186/1477-7517-10-10. [PubMed: 23786800]. [PubMed Central: PMC3695813].

25. US Department of Health and Human Service. Quick guide to health literacy. [cited 2020 Feb 4]. Available from: https://health.gov/ communication/literacy/quickguide/factsbasic.htm.

26. Lankarani KB, Ardebili M, Sepehrimanesh M, Nejabat M, Hemmati Rad MA, Hosseini SY. Evaluation of hepatitis $C$ virus intrafamilial transmission among families with one index case, a pilot study from Fars province, Iran. Gastroenterol Hepatol Bed Bench. 2016;9(4):250-8. [PubMed: 27895850]. [PubMed Central: PMC5118849]. 